\title{
Design of demand driven return supply chain for high-tech products
}

\author{
Jalal Ashayeri ${ }^{1}$, Gülfem Tuzkaya $^{2}$ \\ ${ }^{1}$ Tilburg University (THE NETHERLANDS), ${ }^{2}$ Yildiz Technical University (TURKEY) \\ j.ashayeri@uvt.nl; gtuzkaya@yildiz.edu.tr
}

Received June 2010

Accepted September 2011

\section{Abstract:}

Purpose: The purpose of this study is to design a responsive network for after-sale services of high-tech products.

Design/methodology/approach: Analytic Hierarchy Process (AHP) and weighted max-min approach are integrated to solve a fuzzy goal programming model.

Findings: Uncertainty is an important characteristic of reverse logistics networks, and the level of uncertainty increases with the decrease of the products' life-cycle.

Research limitations/implications: Some of the objective functions of our model are simplified to deal with non-linearities.

Practical implications: Designing after-sale services networks for high-tech products is an overwhelming task, especially when the external environment is characterized by high levels of uncertainty and dynamism. This study presents a comprehensive modeling approach to simplify this task.

Originality/value: Consideration of multiple objectives is rare in reverse logistics network design literature. Although the number of multi-objective reverse logistics network design studies has been increasing in recent years, the last two objective of our model is unique to this research area. 
Keywords: after-sale services, reserve logistics, AHP, weighted max-min approach, fuzzy goal-programming

\section{Introduction}

The worldwide high-tech products market is one of the most dynamic industrial segments. High-tech supply chains, particularly the electronics, operate at one hand directly with consumers and on other hand with the industrial markets. For both markets, responsiveness in forward and reverse chains is a prerequisite. With sharp decline in the profit margins, the after-sales services and activities to support consumers and the product disposal have become not only a source of profit but also a key differentiation for customer satisfaction. Here, we describe some of the return flow challenges in the high-tech supply chain of business to consumer (B2C) nature and make suggestions for improving the long-term return network design decisions. These flows are mainly warranty and service returns. After sales returns are endemic in high-tech, with rates as high as $20 \%$ in some sectors (Thrikutam \& Kumar, 2004) and the industry global nature requires many high-tech supply chain examine carefully their Return Supply Chain flows (RSC) (Cheng \& Lee, 2010). Also from the economic point of view, according to the Bundschuh and Dezvane (2003), after sales services market has been found to be up to four or five times larger than the market for new products.

In general, the RSC network design challenges are: (a) customer related, these are usually related to customer return order cycle time (on time to request) and flexibility and adaptability of return/repair operations to the changing market requirements; (b) cost related, this requires maintaining cheapest cost solution while customer service is not endangered; and finally (c) asset related, here the idea is to better utilize the fixed assets in order to meet financial requirements. Currently, all three are priorities for high-tech RSC.

The short-life cycle of products due to high level of technical and market uncertainties; rapidly declining prices (D'Cruz, 2010); and rapid technological obsolescence (White et al., 2003) all have an amplifying effect on the uncertainties and degree of returns. Therefore, repair centers are increasingly "demand driven". Under such circumstances, minimal inventories of components and parts are maintained and most of it is circulating, thus the increasing importance of the location and transport component in RSC network design decisions. The operational 
management of such a system relies heavily on warehousing management capabilities, advanced information systems, and repair process activities to insure that parts and/or products are delivered to repair centers when required (on demand) and repaired products are sent back to consumers within the requested lead-time (on time).

Summarizing the situation, the design of RSC is rather involved multi-objective problem. The return responsiveness not only impacts the customer satisfaction but also on the increased forward demand. This responsiveness is a function of the size, location, and utilization of collection and repair centers. For example, the likely exponential increase in return demand in the early phase of product introduction, requires proximity of collection centers to the market regions, so that a pool of returned products are quickly checked and dispatched to repair-centers. The proper sizing and a balanced utilization of repair centers would avoid bottlenecks and impact the speed of the return flow. Therefore, the RSC design is a strategic decision.

Major high-tech chains have restructured their RSC strategies through the introduction of outsourcing the return flow and services, centralized (outsourced) repair centers with a number of collection centers, see for example Cheng and Lee (2010). Centralization is not always best solution; it might reduce the overall costs but not necessarily increase the responsiveness and demand driven nature of repair centers. The multi-echelon and the multi-objective nature of RSC design problem is mostly overlooked in the process of outsourcing. And the third-party providers usually focus on optimizing own entire activities, rather than a particular client. Therefore, analyzing such a problem is important to the companies owning own RSC and those that have subcontracted it as a mean to measure the subcontractor's performance.

The problem of locating return centers has attracted considerable attention of the academicians and practitioners recently. When the current literature investigated, it can be concluded that most of the RSC network design problems are modeled in deterministic environment (Srivastava, 2008; Yongsheng \& Shouyang, 2008; Beamon \& Fernandes, 2004; Pishvaee et al., 2010). However, the uncertain nature of the reverse logistics environment has not been considered very often until now. As Qin and Ji (2010) suggest, uncertainty is one of the characteristics of logistics networks with product recovery. Earlier Lee and Dong (2009) stated that it would be useful to have a comprehensive quantitative study concerning the impact of uncertainty on recovery network design and the appropriateness of traditional 
approaches for capturing this element. Even though some common denominators can be found, the uncertainties of the design environment vary from one case to another case. Demand (or quantity) uncertainty Zhang et al. (2010), Xiao et al. (2010), Qin and Ji (2010), Amaro and Barboso-Povoa (2009), Lee and Dong (2009), Chouinard et al. (2008), El-Sayed et al. (2010), Salema et al. (2007), Biehl et al. (2007), quality uncertainty (Qin \& Ji, 2010 ; Chouinard et al., 2008) price uncertainty (Amaro \& Barboso-Povoa, 2009), lead times or timing uncertainty (Lieckens \& Vandaele, 2007; Biehl et al., 2007) are some of the investigated uncertainty dimensions of return networks. The modelling efforts to include these uncertainty dimensions vary. Here we have highlighted a few approaches along with the type of uncertainties considered (Table 1).

As can be seen from Table 1, consideration of uncertainty in the RSC literature is relatively new and the number of papers has been increasing in the recent years. Under the category of robust optimization, Realff et al. (2000) propose a model trying to minimize the maximum deviation of the performance of the network from the optimal performance under a number of different return scenarios for used carpet RSC. A supplementary study was proposed by Realff et al. (2004) utilizing robust optimization where demand decays with distance from collection centers. Hong et al. (2006) propose a scenario based robust optimization model for supporting strategic e-scrap reverse production infrastructure design decisions under uncertainty.

\begin{tabular}{|c|c|c|c|c|c|}
\hline & \multicolumn{4}{|c|}{ Utilized Techniques } \\
\hline & & $\begin{array}{l}\text { Robust } \\
\text { Optimization }\end{array}$ & $\begin{array}{l}\text { Stochastic } \\
\text { Programming }\end{array}$ & $\begin{array}{l}\text { Fuzzy } \\
\text { Programming }\end{array}$ & Others \\
\hline \multirow{3}{*}{ 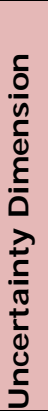 } & Time & - & - & - & $\begin{array}{l}\text { Lieckens \& } \\
\text { Vandaele (2007) }\end{array}$ \\
\hline & Quality & - & $\begin{array}{l}\text { Listeş \& Dekker } \\
(2005)\end{array}$ & - & - \\
\hline & Quantity & $\begin{array}{l}\text { Realff et al. } \\
\text { (2000) } \\
\text { Realff et al. } \\
\text { (2004) } \\
\text { Hong et al. } \\
\text { (2006) }\end{array}$ & $\begin{array}{l}\text { Listeş \& Dekker } \\
\text { (2005) } \\
\text { Listeş (2007) } \\
\text { El-Sayed et al. } \\
\text { (2010) } \\
\text { Chouinard et al. } \\
\text { (2008) } \\
\text { Lee \& Dong (2009) }\end{array}$ & $\begin{array}{l}\text { Qin \& Ji (2010) } \\
\text { Zhang et al. } \\
(2010)\end{array}$ & $\begin{array}{l}\text { Biehl et al. (2007) } \\
\text { Salema et al. } \\
\text { (2007) } \\
\text { Amaro \& Barbosa- } \\
\text { Povoa (2009) }\end{array}$ \\
\hline
\end{tabular}

Table 1. RSC network design literature overview

As a second category stochastic programming is also used to cope with the uncertainty inherent to RSC systems. Listeş and Dekker (2005) propose a stochastic programming based approach by which a deterministic location model for product recovery network design may be extended to explicitly account for the uncertainties. The objective of the proposed model is net revenue maximization and the uncertainties on the amount and quality of the returned flows are taken 
into account. Listeş (2007) presents a generic stochastic model for the design of networks comprising both supply and return channels organized in a closed loop system. The proposed model accounts for a number of scenarios which may be constructed based on critical levels of design parameters such as demand and return. The objective of the model is net profit maximization and demand-return volume uncertainties are taken into account. El-Sayed et al. (2010) propose multiperiod multi-echelon forward-reverse logistic network design under risk model. The problem is formulated in a stochastic mixed-integer linear programming decision making form as a multi-stage stochastic program. The objective of the model is to maximize the total expected profit and demand uncertainty is taken into account. Chouinard et al. (2008) suggest a stochastic programming model to study the impacts of random factors related to the recovery, processing and demand volumes on the design of supply loops. Their solution approach is based on the sample average approximation with use of Monte Carlo simulation method. The objective of their model is cost minimization and recovery, processing and demand volume uncertainties are taken into account. Lee and Dong (2009) offer a dynamic location allocation model to cope with the factors may vary over time. The proposed model is a two stage stochastic programming model by which a deterministic model for multi-period RSC network design can be extended to account for the uncertainties. The objective of the model is to minimize the total investment and operational costs in the dynamic logistics network. Demand of forward products and the supply of returned products at customers are uncertain.

The third category of papers utilizes fuzzy programming and some other related techniques to handle the uncertainty of RSCs. Among those we can refer to Qin and Ji (2010) and Zhang et al. (2010). They use fuzzy programming to design the product recovery networks. In these studies the volume of returned products are considered as uncertain data.

The fourth category of papers includes a variety of approaches. Lieckens and Vandaele (2007) propose a RSC network design model with stochastic lead times. The model is a mixed integer nonlinear programming model with the combination of queuing model. Biehl et al. (2007) simulate a carpet RSC and use a designed experiment to analyze the impact of the system design factors as well as environmental factors impacting the operational performance of the RSC considering highly variable return flows. Salema et al. (2007) propose a generalized model where capacity limits, multi-product management and uncertainty on product demands and returns are considered. They develop a mixed integer formulation and solve it using standard branch and bound technique. A 
similar technique is also used by Amaro and Barbosa-Povoa (2010). They propose a multi-period planning model where the supply chain operational decisions impacts on supply, production, transportation and distribution are measured for given horizon with different demand and price per period.

Numerous papers on forward and a few on reverse supply chain considering network location design are surveyed by Zanjirani Farahani et al. (2010). They made a very detailed review of the literature on multi-criteria facility location. There is however very limited number of papers taking into account simultaneously the uncertainties related to return quantity, quality, and the lead-time.

This paper is organized as follows: In Section 2, we brief the return chains network design of high-tech products. In this section we present the modeling approach. Section 3 presents a fuzzy based multi-objective linear programming solution methodology to solve the problem. Section 4 briefs numerical results. Finally, in Section 5 conclusions are drawn.

\section{Return Supply Chain Network Design: Modeling Approach}

Uncertainty degrees and types depend on the case understudy, for example, in some cases; expected return volume variation may be relatively small for the products with relatively long life-cycles. Such uncertainties can be studied through sensitivity analyses. For high-tech products however return volume is unknown, in general. This return behavior can be easily formulated as different fuzzy sets. Uncertainty can be included in the modeling process in different ways. Ilgın and Gupta (2010) suggest robust optimization and stochastic programming are the most popular techniques implemented to handle uncertainty in RSC network design.

We proposed a Multi-Objective Linear Programming (MOLP) modeling approach based consultation with the experts and related literature, especially, Tuzkaya et al. (2011), Du and Evans (2008), Pishvaee et al. (2010), Chan et al. (2005) and Altıparmak et al. (2006). Our approach, for the most part, provides a mean to make more strategic decision. It addresses the design aspect of the distribution channel, i.e., the establishments of the distribution network and its associated flows. The proposed RSC network model consists of customers, Collection Centers (CC), Repair Centers (RC) and potential flows among them. Based on the customer calls, products are collected by the $\mathrm{CC}$ considering the maximum service coverage area constraint. From CC, returned products are being pooled and sent to the nearest RC considering its capacity constraint. In the RCs, returned products are 
inspected and classified according to repair needs: (i) products which have important defects are rejected, then new products are dispatched to customers or they are reimbursed in full. The rejected products are transported to a disposal center, (ii) products which have slight repair needs (iii) products which have important repair needs with additional repair times and repair costs.

Some assumptions are made as follows:

- It's assumed that spare parts required for the repairable products with relatively more repair needs are brought from manufacturing facilities based on the demand. The replenishment time including the transportation times and repair times are given and known.

- Each customer is assumed to be a group of customers located in close vicinity.

- Transportation costs between a disposal center and RCs are assumed to be included in the disposal costs.

- The total of rejected and repairable products percentages (with slight and important repair needs) is equal to one.

- New product cost for returned products that cannot be repaired (rejected) is a function of collection center from which the products comes and subject to dependencies like currency rate and tax rate.

Return volume from customers, and objective functions' values are considered as fuzzy values. Indices, parameters, decision variables and the details of the model are given as follows:

\section{$\underline{\text { Indices }}$}

m Index for customers $m \in M$

i Index for collection centers (CCs) $i \in I$

j Index for repair centers (RCs) $j \in J$

\section{Parameters}

$D_{m} \quad$ Total return volume per year of customer $\mathrm{m}$

$d_{m i} \quad$ Distance between customer $\mathrm{m}$ and $C C_{i}$

$d_{i j} \quad$ Distance between $C C_{i}$ and $R C_{j}$

tc Unit transportation cost for returns 
$d p c \quad$ Unit disposal cost for rejected products

$t_{m i} \quad$ Transportation time between customer $\mathrm{m}$ and $C C_{i}$

$t_{i j} \quad$ Transportation time between $C C_{i}$ and $R C_{j}$

$t_{\text {INS }} \quad$ Total inspection and classification time in RCS

$t_{S R N} \quad$ Repair time for products with slight repair needs

$t_{I R N} \quad$ Part replenishment and repair times for products with important repair needs

$t_{\text {EXP }} \quad$ Customer expectation on service time (or promised service time to the customers with guarantee contract)

$\mathrm{Cap}_{i} \quad$ Total capacity of $C C_{i}$ per year

$\mathrm{Cap}_{j} \quad$ Total capacity of $R C_{j}$ per year

$R_{i} \quad$ Renting cost of $C C_{i}$ per year

$C_{E S T_{j}} \quad$ Establishment cost of $\mathrm{RC}_{\mathrm{j}}$

$A_{j} \quad$ The weight of $R C_{j}$ obtained via Analytical Hierarchy Process (AHP)

Cins $_{j} \quad$ Unit inspection and classification cost in the $R C_{j}$

$\beta_{\text {REJ }} \quad$ Percentage of rejected products in RCs

$\beta_{S R N} \quad$ Percentage of repairable products with slight repair needs

$\beta_{\text {IRN }} \quad$ Percentage of repairable products with important repair needs

L $\quad$ Arbitrarily set large number

$C_{N P_{i}} \quad$ New product costs in CCi for the returned products that cannot be repaired ( rejected)

$C_{S R N_{j}}$ Repair costs for products which has slight repair needs and can be repaired in RCs

$C_{I R N_{j}} \quad$ Repair costs for products which has important repair needs in RCs

$\underline{\text { Variables }}$

$Y_{i} \quad$ Renting decision of $C C_{i} \quad Y_{i} \in\{0,1\}$

$Z_{j} \quad$ Establishment decision of $R C_{j} \quad Z_{j} \in\{0,1\}$

$Y_{m i} \quad$ Assignment decision of customer $\mathrm{m}$ to $C C_{i} \quad Y_{m i} \in\{0,1\}$

$Z_{i j} \quad$ Assignment decision of $C C_{i}$ to $R C_{j} \quad Z_{i j} \in\{0,1\}$

$X_{m i} \quad$ Total return volume coming from customer $\mathrm{m}$ to $C C_{i}$ 
$X_{i j} \quad$ Total return volume coming from $C C_{i}$ to $R C_{j}$

Four objectives are considered in the proposed RSC network design model: (1) cost minimization (2) maximization of weighted assignments to RCs, (3) minimization of tardiness in the customer service (4) maximization of average capacity utilization levels.

First objective (OF1): net cost minimization

The first objective function is cost minimization (Equation 1). This function includes transportation cost, CC renting cost, RC establishment cost, inspectionclassification-overhauling cost, new product costs for rejected repairs, repairing costs in RCs.

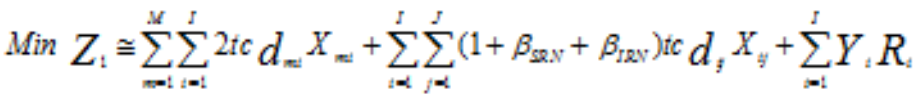

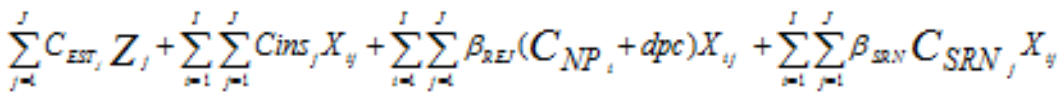

$$
\begin{aligned}
& +\sum_{j=1}^{J} \sum_{j=1}^{J} \beta_{\text {IRN }} C_{I R N_{j}} X_{t j}
\end{aligned}
$$

The components of the first objective function can be explained as below.

The total transportation costs from customers to the CCs, from the CCs to the RCs can be represented as Equations 2-3, respectively.

$$
\begin{aligned}
& \sum_{m=1}^{M} \sum_{i=1}^{I} 2 t c d_{m i} X_{m i} \\
& \sum_{i=1}^{I} \sum_{j=1}^{J}\left(1+\beta_{S R N}+\beta_{I R N}\right) t c d_{i j} X_{i j}
\end{aligned}
$$

Total renting or annuity costs for selected CCs can be represented as Equation 4.

$$
\sum_{i=1}^{I} Y_{i} R_{i}
$$

Establishment costs of the RCs can be represented as Equation 5.

$$
\sum_{j=1}^{J} C_{E S T_{j}} Z_{j}
$$

Total inspection, classification costs in RCs can be represented as Equation 6. 


$$
\sum_{i=1}^{I} \sum_{j=1}^{J} \operatorname{Cins}_{j} X_{i j}
$$

Total costs of rejected products (new products need to be given to the customers and disposal needs for the rejected ones) can be represented as Equation 7.

$$
\sum_{i=1}^{I} \sum_{j=1}^{J} \beta_{R E J}\left(C_{N P_{i}}+d p c\right) X_{i j}
$$

Total cost of products needed slight repairing (slight repair needs can be solved in RCs) as Equation 8.

$$
\sum_{i=1}^{I} \sum_{j=1}^{J} \beta_{S R N} C_{S R N_{j}} X_{i j}
$$

Total cost of products needed important repairing as Equation 9.

$$
\sum_{i=1}^{I} \sum_{j=1}^{J} \beta_{I R N} C_{I R N_{j}} X_{i j}
$$

Second objective (OF2): maximization of weighted product volume assigned from CCs to RCs

The second objective function is the maximization of the weighted product volume assigned from CCs to RCs (Equation 10). Here, the weighting for the qualitative factors is realized for RCs via AHP.

$$
\operatorname{Max} Z_{2} \cong \sum_{i=1}^{I} \sum_{j=1}^{J} A_{j} X_{i j}
$$

Third objective function (OF3): total tardiness minimization

The third objective function is the minimization of the total tardiness from the customers expected service time (i.e. promised service time in guarantee contract) (Equation 11). 


$$
\min Z_{3} \cong\left\{\begin{array}{l}
{\left[\sum_{j=1}^{I}\left(2 \sum_{m=1}^{M} t_{m i} X_{m i}+\sum_{j=1}^{S}\left(t_{i j}+t_{I N S}-t_{E X P}\right) X_{i j}\right)\right] \beta_{R E S}+} \\
\left.\left[\sum_{m=1}^{M} t_{m i} X_{m i}+\sum_{j=1}^{J}\left(2 t_{i j}+t_{I N S}+t_{S R N}-t_{E X P}\right) X_{i j}\right)\right] \beta_{S R N}+ \\
{\left[\sum_{i=1}^{S}\left(2 \sum_{m=1}^{M} t_{m i} X_{m i}+\sum_{j=1}^{J}\left(2 t_{i j}+t_{I N S}+t_{I R N}-t_{E X P}\right) X_{i j}\right)\right] \beta_{I R N}}
\end{array}\right\}
$$

Fourth objective function (OF4): equity on capacity utilization

With the fourth objective function, total average capacity utilization levels of RCs are tried to be maximized (Equation 12).

$$
\max Z_{4} \cong\left(\sum_{i=1}^{I} X_{i 1} / \operatorname{Cap}_{1}+\sum_{i=1}^{I} X_{i 2} / \operatorname{Cap}_{2}+\ldots+\sum_{i=1}^{I} X_{i J} / \operatorname{Cap}_{J}\right) / J
$$

\section{Constraints}

Equations 13 guarantee that each customer's demand is satisfied.

$$
\sum_{i=1}^{I} X_{m i}=\tilde{D}_{m} \quad \forall m \in M
$$

Equations 14 secure only when CC is opened, a customer can be assigned to this CC.

$$
Y_{m i} \leq Y_{i} \quad \forall m \in M \text { and } \forall i \in I
$$

Equations 15 permit customer flow volume to CC only if the customer is assigned to $\mathrm{CC}$.

$$
X_{m i} \leq L Y_{m i} \quad \forall m \in M \text { and } \forall i \in I
$$

Equations 16 guarantee that the incoming product volume of the $\mathrm{CC}$ is equal to the outgoing product volume of that CC.

$$
\sum_{m=1}^{M} X_{m i}=\sum_{j=1}^{J} X_{i j} \quad \forall i \in I
$$


Equations 17 ensure that a CC cannot be assigned to this RC if this RC is not established.

$$
Z_{i j} \leq Z_{j} \quad \forall i \in I \text { and } \forall j \in J
$$

Equations 18 represent that if a CC is not assigned to a RC, an assignment product volume does not occur.

$$
X_{i j} \leq L Z_{i j} \quad \forall i \in I \text { and } \forall j \in J
$$

Equations 19 guarantee that each customer is assigned to only one CC, Equations 20 assure that each CC is assigned to only one RC.

$$
\begin{aligned}
& \sum_{i=1}^{I} Y_{m i} \leq 1 \quad \forall m \in M \\
& \sum_{j=1}^{J} Z_{i j} \leq 1 \quad \forall i \in I
\end{aligned}
$$

Equations 21 and 22 are the capacity constraints of the $C C_{i}$ and the $R C_{j}$, respectively.

$$
\begin{aligned}
& \sum_{m=1}^{M} X_{m i} \leq \operatorname{Cap}_{i} \quad \forall i \in I \\
& \sum_{i=1}^{I} X_{i j} \leq \operatorname{Cap}_{j} \quad \forall j \in J
\end{aligned}
$$

Equations 23-24 represent non-negativity constraints.

$$
\begin{array}{ll}
X_{m i} \geq 0 & \forall m \in M \text { and } \forall i \in I \\
X_{i j} \geq 0 & \forall i \in I \text { and } \forall j \in J
\end{array}
$$

Equations 25 represent binary variables.

$$
Y_{m i}, Y_{i}, Z_{i j}, Z_{j} \in\{0,1\} \quad \forall m \in M, \forall i \in I \text { and } \forall j \in J
$$




\section{Methodology}

An integrated Analytical Hierarchy Process (AHP) and weighted max-min approach is utilized in this study. Objective function and repair center weights are calculated via AHP. Using these weights and input data, Fuzzy Goal Programming (FGP) model is solved via weighted max-min approach.

\subsection{AHP approach for objective functions and repair centers evaluations}

In order to calculate the objective function weights, AHP approach is utilized (Saaty, 1980). Our four objectives weights are calculated via pair wise comparisons with respect to their contribution to the main objective (to find best RSC network for the decision makers (DM)).

Repair centers' weights are calculated considering the criteria obtained from Tuzkaya and Gülsün (2008), Tuzkaya, Gülsün and Önsel (2011). The evaluation criteria are transportation, environmental, social-political, economical and technical. Similar to objective function weighting, for this purpose the DM preferences for pair-wise comparison are solicited.

\subsection{Weighted max-min method}

In this study, we utilized the FGP approach of Lin (2004). A FGP model with $m$ goal can be represented as in Equation 26:

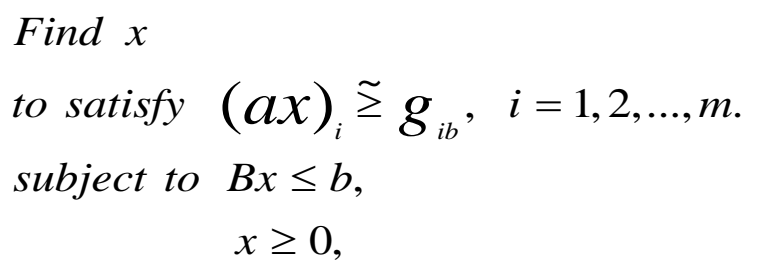

where $\mathrm{x}$ is an $\mathrm{n}$-vector with components $\mathrm{x}_{1}, \mathrm{x}_{2}, \ldots, \mathrm{x}_{\mathrm{n}}$ and $\mathrm{Bx} \leq b$ are system constraints in vector notation. Since all objectives might not be achieved simultaneously under the system constraints, the decision maker may define a lower tolerance limit and a membership function for each objective to determine the achieved level of that objective.

In the FGP model (Equation 27), objective functions can be weighted considering their relative importance to the achievement of the main aim which is to find best network design for the after sale services. With the weighted objective functions, Equation 26 can be converted to Equation 27, as a one objective linear model with the weighted max-min approach (Lin, 2004; Kongar \& Gupta, 2006). In this 
equation, $\lambda$ is the satisfaction degree of decision makers with the objective functions' obtained values.

$\operatorname{Max} \lambda$

subject to

$$
\begin{aligned}
& W_{i} \lambda \leq f_{i}\left((a x)_{i}\right), \quad \forall i, \\
& B x \leq b, \\
& x \geq 0
\end{aligned}
$$

(a)

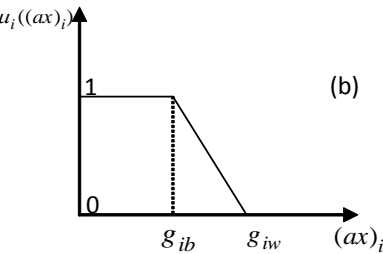

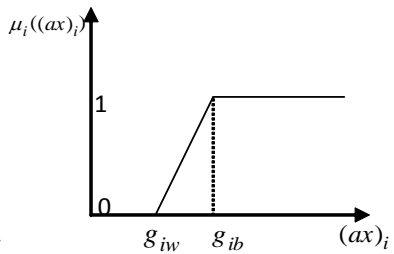

Figure 1. Linear membership functions for minimization (a) and maximization (b) objectives

If the objective functions $(a x)_{i}, i=1,2, \ldots, m$, are expressed as fuzzy sets whose membership functions increase linearly from 0 to 1 (Amid et al., 2011), membership function for a minimization objective (Figure 1a) can be expressed as in Equation 28.

$$
\mu_{i}\left((a x)_{i}\right)=\left\{\begin{array}{ll}
1 & \text { if }(a x)_{i} \leq g_{i b} \\
\left.(a x)_{i}-g_{i b}\right) /\left(g_{i w}-g_{i b}\right) & \text { if } g_{i b} \leq(a x)_{i} \leq g_{i w} \\
0 & \text { if }(a x)_{i} \geq g_{i w}
\end{array}\right\}
$$

Membership function for a maximization objective (Figure 1b) can be expressed as in Equation 29.

$$
\mu_{i}(a x)_{i}=\left\{\begin{array}{ll}
1 & \text { if }(a x)_{i} \geq g_{i b} \\
\left(g_{i b}-(a x)_{i}\right) /\left(g_{i b}-g_{i b}\right) & \text { if } g_{i w} \leq(a x)_{i} \leq g_{i b} \\
0 & \text { if }(a x)_{i} \leq g_{i w}
\end{array}\right\}
$$

Adapted from Liang (2006, 2009), we can summarize our solution methodology as follows.

Step 1. Formulate the original fuzzy MOLP model,

Step 2. Specify the best $\left(g_{i b}\right)$ and worst $\left(g_{i w}\right)$ objective values for each objective i. In this study, best objective values are found solving the model for each objective separately. The worst values are obtained between solutions of calculating other objective values in the one objective solution, 
Step 3. Specify the degree of membership $f_{i}\left((a x)_{i}\right)$ for each objective i,

Step 4. To convert the FGP approach to an equivalent linear programming model, introduce the auxiliary variable $\lambda$,

Step 5. Calculate the weight of objective functions and repair centers using AHP,

Step 6. Solve the linear programming model.

\section{Numerical Results}

In this study, a hypothetical case of a LCD-monitor return supply chain network design is solved. In this example, for the after sales services we consider twenty customers clusters, four collection centers, three repair centers. Input data related with distances, transportation times between nodes and demand of customers for one planning period, yearly rental costs of collection centers and establishment costs of repair centers are shown in Table 2. Unit inspection costs for RC1, RC2 and $\mathrm{RC} 3$ are 5, 5.5 and 6 Euros, respectively; new product costs from CC1, CC2, CC3 and CC4 are 1500, 1550, 1570 and 1530 Euros, respectively. The product costs are assumed to include disposal cost for the rejected returns. Repair costs for the products which need slightly repairs in RC1, RC2, RC4 are 30, 50, 35 Euros, respectively. Repair costs for the products which need important repairs in RC1, RC2, RC4 are 200, 230, 210 Euros, respectively. The percentages of returns which are rejected, need slightly repair, and important repair are 5\%, $70 \%$ and $25 \%$ respectively. Capacities of CC1, CC2, CC3, CC4, RC1, RC2, RC3 are 25000, 25000, 25000, 25000, 20000, 30000 and 40000 units, respectively. Arbitrarily set large number $\mathrm{L}$ is taken as 5000000 .

Objective functions are evaluated via AHP and their weights are obtained as 0.56 for OF1, 0.06 for OF2, 0.12 for OF3 and 0.26 for OF4. Additionally, repair centers are evaluated via AHP and their weights (these weights are used as $A_{j}$ parameters of the second objective function) are obtained as 0.61 for RC1, 0.21 for RC2 and 0.18 for RC3.

Although distances between nodes have an important effect on return times, they are also assumed to be influenced by the road conditions and transportation types. Hence, vehicle transportation times per km are not same for the every route.

\subsection{Analyses and Discussion}

To construct the membership functions of objective functions, first the model is solved separately for each objective. By doing this, best values are obtained. Secondly, objective function values are obtained for the other objectives' global 
solutions. Between these values, the worst one for each objective is the objective's worst value. These results are summarized as in Table 3.

After constructing the membership functions, problem is solved with integrated AHP-weighted max-min approach via Lingo 9.0 solver program. Obtained results are summarized in Tables 4, 5, 6, 7, 8 and 9 for different objective function weight combinations. First objective weight combination is $W=(0.56,0.06,0.12,0.26)$ and these weights are the results of AHP and DM preferences. In this weight combination, all collection centers are supposed to be rented (Table 4, 5 and 6). However, with the change in the objective function weight combinations, those assignment volumes are observed to be changed. As an example, while weight of OF1 is decreasing, the assignment volume to CC3 is increasing since the rental cost of this collection center is the most expensive one and the assigned volume is low when total cost is important.

When repair center's assignments are considered, it is observed that first two repair centers are decided to be opened for all objective function weight combinations (Table 7, 8 and 9). Also, while the second objective function's weight is increasing, the assignment volume of RC1 is increasing similarly. It is an expected situation, since the second objective is the weighted assignment maximization to the repair centers and the RCl has the biggest weight between the others. All these analyses show the sensitivity of the model to the parameter changes.

\begin{tabular}{|c|c|c|c|c|c|c|c|c|c|c|c|c|c|c|c|}
\hline & \multicolumn{6}{|c|}{ Distance ( km) } & \multicolumn{5}{|c|}{ Distance (km) } & \multicolumn{4}{|c|}{ Transportation time (hr) } \\
\hline & $\mathrm{CC} 1$ & $\mathrm{CC} 2$ & $\mathrm{CC} 3$ & CC4 & $\begin{array}{l}\text { Demand } \\
\text { (unit/ year) }\end{array}$ & & CC1 & CC2 & CC3 & CC4 & & CC1 & $\mathrm{CC2}$ & $\mathrm{CC} 3$ & CC4 \\
\hline C1 & 321 & 250 & 528 & 225 & 3585 & RC1 & 151 & 269 & 307 & 288 & C1 & 5.35 & 3.57 & 7.04 & 5 \\
\hline C2 & 313 & 213 & 335 & 445 & 548 & RC2 & 100 & 219 & 258 & 437 & C2 & 5.22 & 3.04 & 5.58 & 4.68 \\
\hline C3 & 318 & 338 & 503 & 113 & 768 & RC3 & 271 & 409 & 275 & 495 & C3 & 5.3 & 4.83 & 8.38 & 1.19 \\
\hline C5 & 332 & 476 & 424 & 225 & 731 & & $\mathrm{CCl}$ & $\mathrm{CC} 2$ & $\mathrm{CC} 3$ & CC4 & C5 & 4.15 & 7.93 & 8.48 & 2.37 \\
\hline C6 & 273 & 416 & 364 & 185 & 1306 & RC1 & 1.68 & 2.99 & 3.41 & 4.11 & c6 & 3.41 & 6.93 & 7.28 & 3.08 \\
\hline C7 & 293 & 422 & 455 & 126 & 4008 & RC2 & 1.43 & 3.13 & 4.3 & 7.28 & C7 & 3.66 & 4.96 & 9.1 & 2.1 \\
\hline $\mathbf{C 8}$ & 282 & 423 & 371 & 173 & 2004 & RC3 & 3.61 & 5.45 & 3.67 & 8.25 & $\mathbf{c 8}$ & 5.64 & 4.98 & 4.12 & 2.88 \\
\hline C9 & 130 & 130 & 149 & 372 & 1702 & & \multicolumn{4}{|c|}{ Rental cost $(€ /$ year $)$} & C9 & 2.6 & 1.53 & 1.66 & 9.3 \\
\hline C13 & 120 & 145 & 168 & 287 & 964 & CC4 & & & & 35000 & C13 & 1.33 & 2.9 & 1.68 & 4.42 \\
\hline C14 & 100 & 151 & 207 & 288 & 9106 & & \multicolumn{4}{|c|}{ Establishment costs $(€)$} & C14 & 2.5 & 3.02 & 2.07 & 4.43 \\
\hline C15 & 251 & 160 & 410 & 339 & 2100 & RC1 & \multicolumn{4}{|c|}{4000000} & C15 & 6.28 & 5.33 & 4.1 & 5.22 \\
\hline C16 & 250 & 120 & 371 & 320 & 755 & RC2 & \multicolumn{4}{|c|}{5000000} & C16 & 6.25 & 4 & 6.18 & 4.92 \\
\hline C17 & 266 & 128 & 379 & 367 & 386 & RC3 & \multicolumn{4}{|c|}{5500000} & C17 & 6.65 & 4.27 & 6.32 & 6.12 \\
\hline C18 & 246 & 95 & 366 & 399 & 2053 & & & & & & C18 & 4.1 & 1.27 & 6.1 & 6.65 \\
\hline C19 & 174 & 29 & 263 & 355 & 2835 & & & & & & C19 & 2.9 & 0.39 & 5.84 & 5.92 \\
\hline C2O & 193 & 45 & 270 & 346 & 6020 & & & & & & C2O & 3.22 & 0.6 & 6 & 5.77 \\
\hline
\end{tabular}

Table 2. Input data for the high-tech after sale services network design problem 


\begin{tabular}{|c|c|c|c|c|}
\hline Objective function type & Minimization & Maximization & Minimization & Maximization \\
\hline & OF1 & OF2 & OF3 & OF4 \\
\hline OF1 (ax) 1 (Euros) & $\begin{array}{l}61,198,930 \\
\text { (best value) }\end{array}$ & 18,021 & $3,450,535$ & 0.6411 \\
\hline OF2- $(a x)_{2}$ (units) & $\begin{array}{l}86,135,632 \\
\text { (worst value) }\end{array}$ & $\begin{array}{r}18,093 \\
\text { (best value) }\end{array}$ & $3,652,103$ & 0.6421 \\
\hline OF3- $(a x)_{3}$ (hours) & $68,891,111$ & $\begin{array}{r}17,837 \\
\text { (worst value) }\end{array}$ & $\begin{array}{r}3,426,533 \\
\text { (best value) }\end{array}$ & $\begin{array}{r}0.6298 \\
\text { (worst value) }\end{array}$ \\
\hline OF4- $(a x)_{4}$ (units) & $83,997,935$ & 18,093 & $\begin{array}{r}3,659,867 \\
\text { (worst value) }\end{array}$ & $\begin{array}{r}0.6421 \\
\text { (best value) }\end{array}$ \\
\hline Multi-objective solution & $73,221,000$ & 17,851 & $3,685,762$ & 0.6387 \\
\hline
\end{tabular}

Table 3. Best and worst values for objective functions

\begin{tabular}{|c|c|c|c|c|c|}
\hline \multicolumn{6}{|c|}{$\begin{array}{l}\text { Objective function weights obtained via AHP } \\
W=(0.56,0.06,0.12,0.26)\end{array}$} \\
\hline & CC1 & CC2 & CC3 & CC4 & TOTAL \\
\hline C 1 & & & & 3585 & 3585 \\
\hline C 2 & 548 & & & & 548 \\
\hline C 3 & 768 & & & & 768 \\
\hline C 4 & 705 & & & & 705 \\
\hline C 5 & & & 731 & & 731 \\
\hline C 6 & & & & 1306 & 1306 \\
\hline C 7 & & & & 4008 & 4008 \\
\hline C 8 & 2004 & & & & 2004 \\
\hline C 9 & & & & 1702 & 1702 \\
\hline C 10 & & & & 3676 & 3676 \\
\hline C 11 & & & & 1411 & 1411 \\
\hline C 12 & & & & 3125 & 3125 \\
\hline C 13 & 964 & & & & 964 \\
\hline C 14 & 9106 & & & & 9106 \\
\hline C 15 & & 2100 & & & 2100 \\
\hline C 16 & & 755 & & & 755 \\
\hline C 17 & & 386 & & & 386 \\
\hline C 18 & 2053 & & & & 2053 \\
\hline C 19 & & & 2835 & & 2835 \\
\hline C 20 & & 6200 & & & 6020 \\
\hline TOTAL & 15380 & 9261 & 3566 & 19581 & 47788 \\
\hline
\end{tabular}

Table 4. Flows between customers and collection centers. Objective function weights obtained via AHP

\begin{tabular}{|c|c|c|c|c|c|}
\hline \multicolumn{6}{|c|}{$\begin{array}{l}\text { Equal objective function weights } \\
W=(0.25,0.25,0.25,0.25)\end{array}$} \\
\hline & CC1 & CC2 & CC3 & CC4 & TOTAL \\
\hline C 1 & & & & 3585 & 3585 \\
\hline C 2 & 548 & & & & 548 \\
\hline C 3 & 768 & & & & 768 \\
\hline C 4 & & 705 & & & 705 \\
\hline C 5 & & & 731 & & 731 \\
\hline C 6 & & & & 1306 & 1306 \\
\hline C 7 & & & & 4008 & 4008 \\
\hline C 8 & 2004 & & & & 2004 \\
\hline C 9 & & & & 1702 & 1702 \\
\hline C 10 & & & & 3676 & 3676 \\
\hline C 11 & & & & 1411 & 1411 \\
\hline C 12 & & & & 3125 & 3125 \\
\hline C 13 & & & & 964 & 964 \\
\hline C 14 & 9106 & & & & 9106 \\
\hline C 15 & & 2100 & & & 2100 \\
\hline C 16 & 755 & & & & 755 \\
\hline C 17 & & 386 & & & 386 \\
\hline C 18 & 2053 & & & & 2053 \\
\hline C 19 & & 2835 & & & 2835 \\
\hline C 20 & & & 6020 & & 6020 \\
\hline TOTAL & 15234 & 6026 & 6751 & 19777 & 47788 \\
\hline
\end{tabular}

Table 5. Flows between customers and collection centers. Equal objective function weights 


\begin{tabular}{|c|c|c|c|c|c|}
\hline \multicolumn{6}{|c|}{$\begin{array}{l}\text { Reverse objective function weights of AHP results } \\
W=(0.06,0.56,0.22,0.12)\end{array}$} \\
\hline & CC1 & CC2 & CC3 & CC4 & TOTAL \\
\hline C 1 & 3585 & & & & 3585 \\
\hline C 2 & & & 548 & & 548 \\
\hline C 3 & 768 & & & & 768 \\
\hline C 4 & & 705 & & & 705 \\
\hline C 5 & & 731 & & & 731 \\
\hline C 6 & & 1306 & & & 1306 \\
\hline C 7 & & & 4008 & & 4008 \\
\hline C 8 & 2004 & & & & 2004 \\
\hline C 9 & 1702 & & & & 1702 \\
\hline C 10 & & & & 3676 & 3676 \\
\hline C 11 & & 1411 & & & 1411 \\
\hline C 12 & & 3125 & & & 3125 \\
\hline C 13 & & 964 & & & 964 \\
\hline C 14 & 9106 & & & & 9106 \\
\hline C 15 & & & & 2100 & 2100 \\
\hline C 16 & & & & 755 & 755 \\
\hline C 17 & & 386 & & & 386 \\
\hline C 18 & & 2053 & & & 2053 \\
\hline C 19 & 2835 & & & & 2835 \\
\hline C 20 & & & 6020 & & 6020 \\
\hline TOTAL & 20000 & 10681 & 10576 & 6531 & 47788 \\
\hline
\end{tabular}

Table 6. Flows between customers and collection centers. Reserve objective function weights of AHP results

\begin{tabular}{|c|c|c|c|c|c|}
\hline \multicolumn{6}{|c|}{$\begin{array}{l}\text { Objective function weights obtained via AHP } \\
W=(0.56,0.06,0.12,0.26)\end{array}$} \\
\hline & CC1 & CC2 & CC3 & CC4 & TOTAL \\
\hline RC1 & & & & 19581 & 19581 \\
\hline RC2 & 15380 & 9261 & 3566 & & 28207 \\
\hline RC3 & & & & & 0 \\
\hline TOTAL & 15380 & 9261 & 3566 & 19581 & 47788 \\
\hline
\end{tabular}

Table 7. Flows between collection centers and repair centers. Objective function weights via AHP

\begin{tabular}{|c|c|c|c|c|c|}
\hline \multicolumn{6}{|c|}{$\begin{array}{l}\text { Equal objective function weights } \\
W=(0.25,0.25,0.25,0.25)\end{array}$} \\
\hline & CC1 & $\mathrm{CC2}$ & CC3 & CC4 & TOTAL \\
\hline RCl & & & & 19777 & 19777 \\
\hline RC2 & 15234 & 6026 & 6751 & & 28011 \\
\hline RC3 & & & & & 0 \\
\hline TOTAL & 15234 & 6026 & 6751 & 19777 & 47788 \\
\hline
\end{tabular}

Table 8. Flows between collection centers and repair centers. Equal objective function weights

\begin{tabular}{|c|c|c|c|c|c|}
\hline \multicolumn{6}{|c|}{$\begin{array}{l}\text { Reverse objective function weights of AHP results } \\
W=(0.06,0.56,0.22,0.12)\end{array}$} \\
\hline & CC1 & CC2 & CC3 & CC4 & TOTAL \\
\hline RC1 & 20000 & & & & 20000 \\
\hline RC2 & & 10681 & 10576 & 6531 & 27788 \\
\hline RC3 & & & & & 0 \\
\hline TOTAL & 20000 & 10681 & 10576 & 6531 & 47788 \\
\hline
\end{tabular}

Table 9. Flows between collection centers and repair centers. Reserve objective function weights of AHP results

In Table 10, overall satisfaction degrees, membership function and objective function values for different weight combinations are presented. Membership function value of OF4 is more than 0.81 for all combinations because capacity levels of RCs are not very limited and satisfaction of this objective function is easier 
considering the others. However, for all the other objective functions, it can be noted that their weights are almost directly affect their membership function values.

\begin{tabular}{|c|c|c|c|}
\hline & $\begin{array}{l}\text { Objective function weights } \\
\text { obtained via AHP } \\
W=(0.56,0.06,0.12,0.26)\end{array}$ & $\begin{array}{l}\text { Equal objective } \\
\text { function weights } \\
W=(0.25,0.25,0.25,0.25)\end{array}$ & $\begin{array}{l}\text { Reverse objective function } \\
\text { weights of AHP results } \\
W=(0.06,0.56,0.22,0.12)\end{array}$ \\
\hline$\lambda$ & 0.90 & 1.43 & 1.78 \\
\hline $\begin{array}{c}\mu_{1}\left((a x)_{1}\right) \\
(a x)_{1}(\text { Euros })\end{array}$ & $\begin{array}{r}0.51 \\
73462800 \\
\end{array}$ & $\begin{array}{r}0.36 \\
77165840 \\
\end{array}$ & $\begin{array}{r}0.11 \\
83268770.00 \\
\end{array}$ \\
\hline $\begin{array}{c}\mu_{2}\left((a x)_{2}\right) \\
(a x)_{2} \text { (units) }\end{array}$ & $\begin{array}{r}0.35 \\
17927.01 \\
\end{array}$ & $\begin{array}{r}0.65 \\
18004.80 \\
\end{array}$ & $\begin{array}{r}1.00 \\
18093.31 \\
\end{array}$ \\
\hline $\begin{array}{c}\mu_{3}\left((a x)_{3}\right) \\
(a x)_{3} \text { (hours) }\end{array}$ & $\begin{array}{r}0.11 \\
3686145 \\
\end{array}$ & $\begin{array}{r}0.36 \\
3743545 \\
\end{array}$ & $\begin{array}{r}0.46 \\
3767263.00 \\
\end{array}$ \\
\hline $\begin{array}{c}\mu_{4}\left((a x)_{4}\right) \\
(a x)_{4} \text { (units) }\end{array}$ & $\begin{array}{l}0.81 \\
0.64 \\
\end{array}$ & $\begin{array}{l}0.90 \\
0.64\end{array}$ & $\begin{array}{r}1 \\
0.64 \\
\end{array}$ \\
\hline
\end{tabular}

Table 10. Overall satisfaction degrees, membership function and objective functions' values for different weight combinations

\section{Conclusions}

In this study after sale services RSC for high-tech industry is investigated. After detailed literature and field analyses, uncertainties inherent to the high-tech returns, the multi-objective structure of the network design was presented. The main uncertainties are taken into account and a FGP model is developed. This model is converted to an equivalent linear programming model using weighted max-min approach. Objective functions and repair facility location alternatives are evaluated via AHP approach. A compromise solution is obtained with the utilized weighted max-min approach.

The model is in development phase. Considering the need for solution simplicity; some assumptions are made especially related to the third and fourth objectives. For example, regardless of number of opened facilities, average capacity utilization is considered in the fourth objective to avoid nonlinearities. Such simplify assumption must be relaxed and a new formulation is needed.

With utilization of weighted max-min approach, the main aim is to maximize the value of the worst objective. This approach may cause loses about some improvement potentials for the other objective functions. The solution methodology can be more effective with a two phase approach in which a weighted average operator can be utilized in the second phase. With the improved model and twophase approach, there might be a need to employ a meta-heuristic. 


\section{References}

Altıparmak, F., Gen, M., Lin, L., \& Paksoy, T. (2006). A genetic algorithm approach for multi-objective optimization of supply chain networks. Computers \& Industrial Engineering, 51, 196-215. http://dx.doi.org/10.1016/j.cie.2006.07.011

Amaro, A.C.S., \& Barbaso-Povoa, A.P.F.D. (2009). The effect of uncertainty on the optimal closed-loop supply chain planning under different partnerships structure. Computers and Chemical Engineering, 33, 2144-2158. http://dx.doi.org/10.1016/j.compchemeng.2009.06.003

Amid, A., Ghodsypour S.H., \& O’Brien, C. (2011). A weighted max-min model for fuzzy multi-objective supplier selection in a supply chain. International Journal of Production Economics, 131(1), 139-145. http://dx.doi.org/10.1016/j.ijpe.2010.04.044

Beamon, B.M., \& Fernandes C. (2004). Supply-chain network configuration for product recovery. Production Planning \& Control, 15(3), 270-281. http://dx.doi.org/10.1080/09537280410001697701

Biehl, M., Preter, E., Realff, \& M.J. (2007). Assesing performance and uncertainity in developing carpet reverse logistics systems. Computers \& Operations Research, 34, 443-463. http://dx.doi.org/10.1016/i.cor.2005.03.008

Bundschuh R.G., \& Dezvane T.M. (2003). How to make after sale services pay off. The McKinsey Quarterly, 4, 116-127.

Chan, F.T.S., Chung, S.H., \& Wadhwa, S. (2005). A hybrid genetic algorithm for production and distribution. Omega, 33, 345-355. http://dx.doi.org/10.1016/i.omega.2004. 05.004

Cheng, Y.H., \& Lee, F. (2010). Outsourcing reverse logistics of high-tech manufacturing firms by using a systematic decision-making approach: TFT-LCD sector in Taiwan, Industrial Marketing Management, 39(7), 1111-1119. http://dx.doi.org/10.1016/j.indmarman.2009.10.004

Chouinard, M., D'Amours, S., \& Ait-Kadi, D. (2008). A stochastic programming approach for designing supply loops. International Journal of Production Economics, 113, 657-677. http://dx.doi.org/10.1016/j.ijpe.2007.10.023

D'Cruz, C.A. (2010). Strategic analysis tools for high tech marketing, Xodus Business Technological Solutions. www.xodusBTS.com - Accessed 28th J uly 2010. 
Du, F., \& Ewans, G.W. (2008). A bi-objective reverse logistics network analysis for post-sale service. Computers \& Operations Research, 35, 2617-2634.

El-Sayed, M., Afia, N., \& El-Kharbotly, A. (2010). A stochastic model for forwardreverse logistics network design under risk. Computers \& Industrial Engineering, 58(3), 423-431. http://dx.doi.org/10.1016/i.cie.2008.09.040

Hong, I.H., Assavapokee, T., Ammons, J., Boelkins, C., Gilliam, K., Oudit, D., Realff, M., Vannicola, J.M., \& Wongthatsanekorn, W. (2006). Planning the e-scrap reverse production system under uncertainty in the state of Georgia: A case study. IEEE Transactions on Electronics Packaging Manufacturing, 29, 150-162. http://dx.doi.org/10.1109/TEPM.2006.881769

Ilgın, M.A., \& Gupta, S.M. (2010). Environmentally conscious manufacturing and product recovery (ECMPRO): A review of the state of the art. Journal of Environmental Management, 91, 563-591. http://dx.doi.org/10.1016/j.jenvman.2009.09.037

Kongar, E., \& Gupta, S. (2006). Disassembly to order system under uncertainty. Omega, 34, 550-561. http://dx.doi.org/10.1016/i.omega.2005.01.006

Lee, D.H., \& Dong, M. (2009). Dynamic network design for reverse logistics operations under uncertainty. Transportation Research Part E, 45, 61-71. http://dx.doi.org/10.1016/j.tre.2008.08.002

Liang, T.F. (2006). Distribution planning decisions using interactive fuzzy multiobjective linear programming. Fuzzy Sets and Systems, 157, 1303-1316. http://dx.doi.org/10.1016/j.fss.2006.01.014

Liang, T.F. (2009). Fuzzy multi-objective project management decisions using twophase fuzzy goal programming approach. Computers \& Industrial Engineering, 57, 1407-1416. http://dx.doi.org/10.1016/j.cie.2009.07.010

Lieckens, K., \& Vandaele, N. (2007). Reverse logistics network design with stochastic lead time. Computers \& Operations Research, 34, 395-416. http://dx.doi.org/10.1016/i.cor.2005.03.006

Lin, C. (2004). A weighted max-min model for fuzzy goal programming. Fuzzy Sets and Systems, 142, 407-420. http://dx.doi.org/10.1016/50165-0114(03)00092-7

Listeş, O. (2007). A generic stochastic model for supply-and-return network design. Computers \& Operations Research, 34, 417-442. http://dx.doi.org/10.1016/i.cor.2005.03.007 
Listeş, O., \& Dekker, R. (2005). A stochastic approach to a case study for product recovery network design. European Journal of Operational Research, 160, 268287. http://dx.doi.org/10.1016/j.ejor.2001.12.001

Pishvaee, M.S., Farahani, R.Z., \& Dullaert, W. (2010). A memetic algorithm for biobjective integrated forward/reverse logistics network design. Computers \& Industrial Engineering, 37, 1100-1112.

Qin, Z., \& Ji, X. (2010). Logistics network design for product recovery in fuzzy environment. European Journal of Operational Research, 202, 479-490. http://dx. doi.org/10.1016/i.ejor.2009.05.036

Realff, M.J., Ammons, J.C., \& Newton, D. (2000). Strategic design of reverse production systems. Computers and Chemical Engineering, 24, 991-996. http://dx.doi.org/10.1016/S0098-1354(00)00418-X

Realff, M.J., Ammons, J.C., \& Newton, D. (2004). Robust reverse production system design for carpet recycling. IIE Transactions, 36, 767-776. http://dx.doi.org/10.1080/07408170490458580

Saaty, T.L. (1980). Analytical Hierarchy Process: Planning, Priority setting, resource allocation. New York and London: McGraw-Hill International Book Co.

Salema, M.I.G., Barbosa-Povoa, A.P., \& Novais, A.Q. (2007). An optimization model for the design of a capacitated multi-product reverse logistics network with uncertainty. European Journal of Operational Research, 179, 1063-1077. http://dx.doi.org/10.1016/j.ejor.2005.05.032

Srivastava, S.N. (2008). Network design for reverse logistics. Omega, 36(4), 535548. http://dx.doi.org/10.1016/j.omega.2006.11.012

Thrikutam, P., \& Kumar, S. (2004). Turning Returns Management into a Competitive Advantage in Hi-Tech Manufacturing, Infoys Technologies Ltd. http://www.mid-hudsonapics.org/LinkedDocuments/Infosys_Returns_Management_Hitech_Manufacturing.pdf Accessed 28th July 2010.

Tuzkaya, G., \& Gülsün, B. (2008). Evaluating centralized return centers in a reverse logistics network: an integrated fuzzy multi-criteria decision approach. International Journal of Environmental Science and Technology, 5(3), 339-352.

Tuzkaya, G., Gülsün, B., \& Onsel, Ş. (2011). A methodology for the strategic design of reverse logistics networks and its application in the Turkish white goods 
industry. International Journal of Production Research, 49(15), 4543-4571. http://dx.doi.org/10.1080/00207543.2010.492804

White, C.D., Masanet, E., Rosen, C.M., \& Beckman, S.L. (2003). Product recovery with some byte: An overview of management challenges and environmental consequences in reverse manufacturing for the computer industry. Journal of Cleaner Production, 11, 445-458. http://dx.doi.org/10.1016/S0959-6526(02)00066-5

Xiao, T., Shi, K., \& Yang, D. (2010). Coordination of a supply chain with consumer return under demand uncertainty. International Journal of Production Economics, 124, 171-180. http://dx.doi.org/10.1016/j.ijpe.2009.10.021

Yongsheng, Z., \& Shouyang, W. (2008). Generic model of reverse logistics network design. Journal of Transportation Systems Engineering and Information Technology, 8(3), 71-78. http://dx.doi.org/10.1016/S1570-6672(08)60025-2

Zanjirani Farahani, R., SteadieSeifi, M., \& Asgari, N. (2010). Multiple criteria facility location problems: A survey. Applied Mathematical Modelling, 34, 1689-1709. http://dx.doi.org/10.1016/j.apm.2009.10.005

Zhang, L., Wang, Z., Pan, X., \& Dong, T. (2010). Optimization Model for Remanufacturing Logistics Network with Fuzzy Parameters. International Conference on Measuring Technology and Mechatronics Automation. http://doi.ieeecomputersociety.org/10.1109/ICMTMA.2010.696 - Accessed 28th J uly 2010.

Journal of Industrial Engineering and Management, 2011 (www.jiem.org)

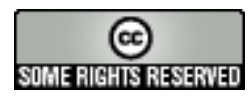

Article's contents are provided on a Attribution-Non Commercial 3.0 Creative commons license. Readers are allowed to copy, distribute and communicate article's contents, provided the author's and Journal of Industrial Engineering and Management's names are included. It must not be used for commercial purposes. To see the complete license contents, please visit http://creativecommons.org/licenses/by-nc/3.0/. 